\title{
Integrated EM (VLF) and Gravity Survey for Delineation of Mineralized Veins in Touzuwa Area of Benue State, Nigeria
}

\author{
Adejuwon .B. Bukola ${ }^{1}$, Salami A.A. ${ }^{2}$, Omatola P.S. ${ }^{2}$, Ashien S.O. ${ }^{2}$, Adeyemo B.K. ${ }^{1}$, and Ujubuonu E.G. ${ }^{1}$ \\ Nigerian Geological Survey Agency, No. 2 Aliyu Makama way, Barnawa Kaduna, Nigeria. \\ 2. KBAB Geosciences' Consult, Prince Avenuem God's own estate, Karshi, Abuja, Nigeria.
}

\begin{abstract}
Mineralized fractures containing lead-zinc and barite in the middle and lower Benue Trough occur in a NWSE or N-S trend within the Cretaceous sediments. Detailed geophysical survey (including gravity and electromagnetic (VLF) methods) were conducted in Touzuwa Benue state underlain by Cretaceous sandstone and shale of the Ezeaku formation for delineation of mineralized veins. The VLF method was applied primarily to delineate the fractures, their trends and lateral extent while the gravity method was targeted at verifying the high density nature of the suspected mineralization.
\end{abstract}

Ten (10) west-east trending traverses were covered using Scintrex EM equipment (ENVI-VLF) at $10 \mathrm{~m}$ station interval and $100 \mathrm{~m}$ traverse separation while five $(5)$ traverses in the same direction were covered using Lacoste and Romberg gravimeter at $50 \mathrm{~m}$ station interval and $200 \mathrm{~m}$ traverse separation. The real components of the VLF data were transformed to filtered-real by applying Fraser filter and this was used to produce the filtered real map.

Several lineaments (veins) of various lengths $(10-100 \mathrm{~m})$, orientation and dip direction which could be host to mineralization were identified from the study. Most of the identified veins are trending $\mathrm{N}-\mathrm{S}$ which are in conformity with the orientation of most mineralized vein in the Benue Trough. The results from the Bouguer Anomaly maps show some areas with distinct positive anomalies indicating the existence of dense materials in the subsurface some of which coincide with the conductive lineament from the VLF result. The VLF method applied suggests that the mineralized veins occur within fracture bodies buried in the cretaceous sediments while the gravity method confirms the dense nature of some of the mineralization.

Keyword: Very Low Frequency (VLF), Scintrex EM Equipment (ENVI-VLF), Lacoste and Romberg Gravimeter

\section{INTRODUCTION}

Mineralized structures mostly fractures containing lead-zinc and barite in the middle and lower Benue Trough occur in a NW-SE or N-S trend within the Cretaceous sediments. They occur as vein infilling materials resulting from fissure in-filling by hydrothermal solution formed by the closing in of the Benue trough during the Santonian (Offodile 1978).
Touzuwa is located about $3 \mathrm{~km}$ southeast of Torkula in Guma local government of Benue state (Fig 1) within the middle benue trough. The study area is about $1 \mathrm{~km}^{2}$. Its accessible through Daudu-Gbajimba road off MakurdiLafia road. It is a relatively flat terrain with maximum elevation of about $146 \mathrm{~m}$ above the sea-level (Figure 2). An attempt is being made to use geophysical methods (integration of EM-VLF and gravity methods) in delineating such reported mineralized structures in the area.

The study area lies within the Middle Benue Trough. The Middle Benue Trough corresponds to the median rectilinear part of the Benue Basin. It extends northeastwards approximately as far as a line joining Bashar and Mutum Biyu. This boundary marks the southern limit of the Gombe and Kerri- Kerri Formations of the Upper Benue Trough. The striking morphological feature is the alluvial plain of the Benue River which occupies the central part of the sedimentary basin (Benkhelil, 1987; Zaborski, 1998).

The area of study falls within the Ezeaku Formation (Fig 3). The deposition of the Ezeaku Formation is attributed to the beginning of marine transgression in the late Cenomanian. The sediments are made up mainly of calcareous shales, micaceous fine to medium friable sandstones and beds of limestones which are in places, shelly. The deposition took place in presumably shallow marine coastal environment.

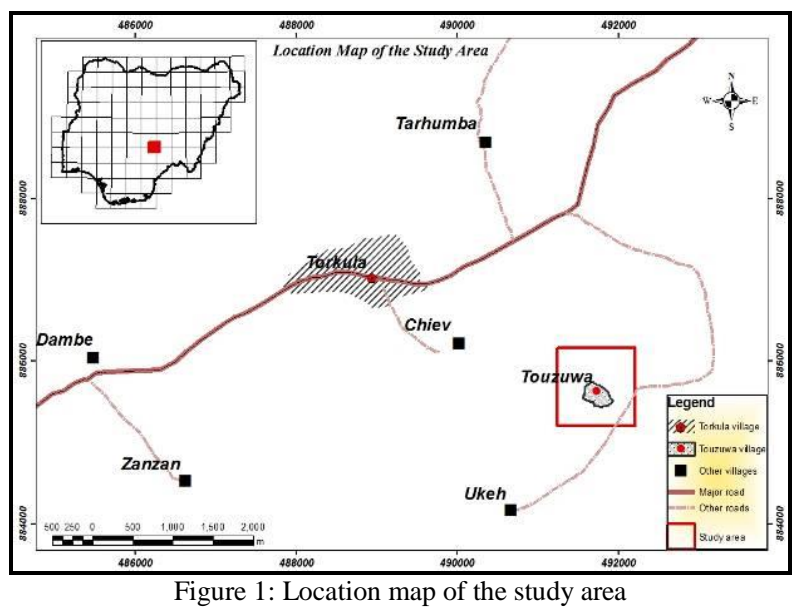




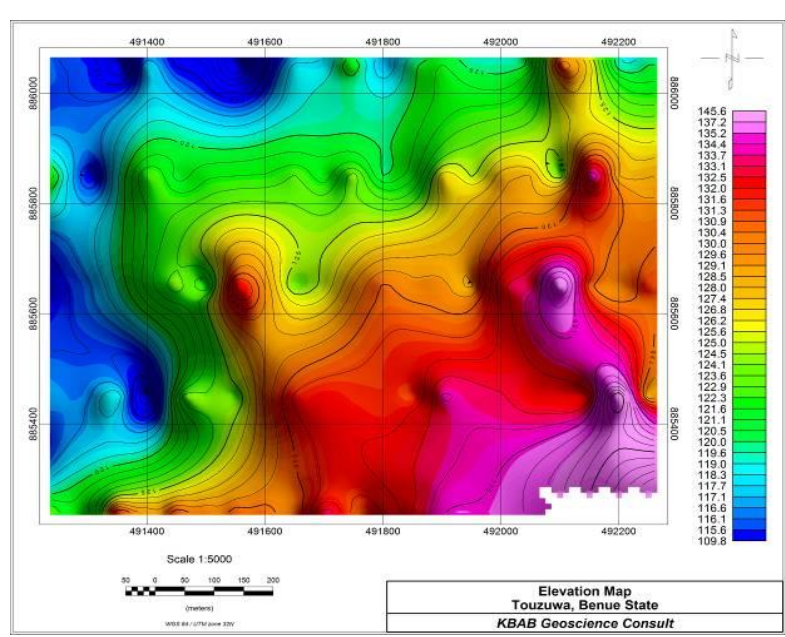

Figure 2: Elevation map of the study area

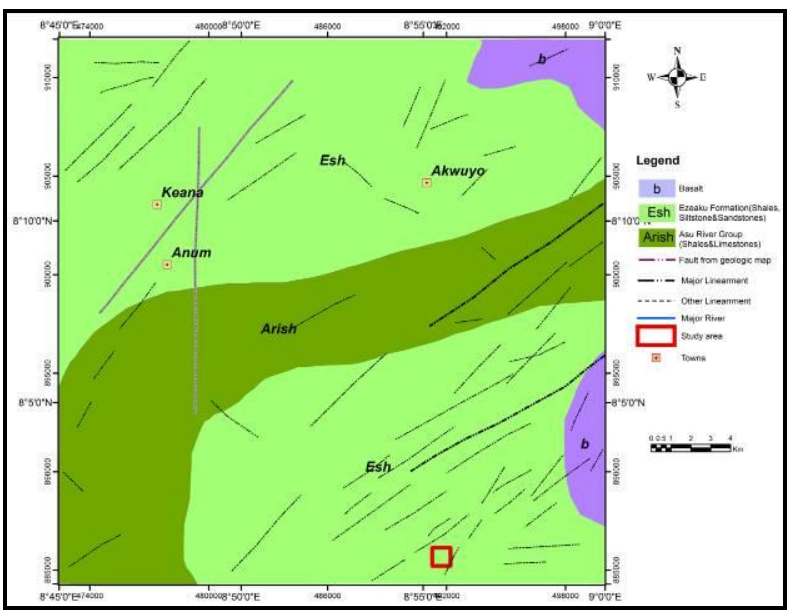

Figure 3: Geological map of 1:50,000 Sheet 231 (Lafia SE) showing Touzuwa within the Ezeaku formation (Adapted from the Geological map of Benue and Nasarawa state. NGSA, 2006).

\section{MATERIALS AND METHODS}

\section{VLF Survey}

Nine east-west traverses were established in the study area at $100 \mathrm{~m}$ traverse separation and $10 \mathrm{~m}$ station position (Fig. 4). These were perpendicular to the regional mineralized structural trend on N/S in the area. Scintrex ENVI-VLF instrument (plate 1) was used to acquire the VLF-EM data with the operator facing the east direction at every station in all the sites. VLF response is a maximum when the target strikes in the direction of the transmitter, falling off roughly as the cosine of the strike angle for other directions (Wightman et al, 2003). In this survey, three signals from Le Blanc, France $(18.3 \mathrm{kHz})$, Rhauderfern, Germany (23.4 $\mathrm{KHz})$ and Italy $(20.3 \mathrm{KHz})$ were adopted daily for the data acquisition because their direction is north of the survey block which is normal to the direction of the expected anomaly thereby given better resolution. The three signals gave the best coupling of the conductors and were very active throughout the period of the survey. The signal from Rhauderfern, Germany $(23.4 \mathrm{KHz})$, the best among the three was chosen for interpretation. The coordinates and heights of the VLF stations were recorded with a Garmin 76 CSX Global Positioning System (GPS) which has accuracy of $\pm 2 \mathrm{~m}$.
The in-phase and quadrature components of the vertical field were plotted for qualitative interpretation (Fig. 5). This is to observe signatures of similar characters simulating a particular geological structure. For VLF survey, the measured data is the affected by topographic relief in hilly areas. Uneven terrain contributes significant anomalies which cause the observed VLF data to depart from the pattern which would be expected on flat ground therefore terrain correction is necessary for such data. Although the study area is gently undulating with the elevation ranges from $110 \mathrm{~m}$ to $145 \mathrm{~m}$ above sea level but topographic correction was carried out to remove such effect on the data base on Eberle (1981) chart. Fraser filter was applied to the real components of the vertical field. This filter calculates horizontal gradients and smoothens the data to give maximum values over conductors. As described by Fraser (1969), the shape of an anomaly along a profile can be convolved with a four-point filter expressed as:

$$
F_{2,3}=\left(I_{4}+\mathrm{I}_{3}\right)-\left(I_{2}+I_{1}\right)
$$

This is plotted midway between the $I_{2}$ and $I_{3}$ stations. This filter operator transforms every genuine cross-over or inflection points of the real component anomaly to positive peaks while the peak becomes negative. The map of filtered real component (Fig. 6) was also produced to show the extent of the genuine conductive targets in the area.

\section{Gravity Survey}

For the gravity survey, five traverses (TR1, 3, 5, 7, and 9) were covered (Fig 4) with traverse separation of $200 \mathrm{~m}$ and station interval of $50 \mathrm{~m}$. A Lacoste and Romberg gravimeter (plates 2), serial number G-512 with reading line of 2.4 and operating temperature of $52.4^{\circ} \mathrm{C}$ was used to measure the relative gravity values all the locations. American Pauline System altimeter (model MDM-5) was used to measure the altimetric height at the gravity station. The altimeter can be read to $0.5 \mathrm{~m}$ accuracy. Psychro-Dyne thermometer (psychrometer) was used to measure the wet and dry temperatures from which the relative humidity was derived using the psychrometric chart. Garmin GPS map 76CSx with an accuracy of $\pm 2 \mathrm{~m}$ was used to record the coordinates of each gravity station using WGS 84 as the datum. The looping time was kept within two hours. The pattern of movement for the adopted looping system was the "closed loop" sequence in which all the loops for a particular day were either chained or looped into one another in a kind of cascade and the first reading for the day always started from a base station (Osazuwa, 1985, 1992). The result of every day's work was sketched on the field to make sure that the loop was properly run and that there were no redundant data. This kind of sequence is compatible with the Geotools Gravmaster software used for the data processing. Gravity differences due to instrumental drift and tidal effects were monitored together by a repeated reading taken at the base station every 2 hours. The gravity data were tied to IGSN '71 (Morelli et al, 1974) through one of the secondary order gravity stations established by NGSA near Torkula village. 
Gravity data processing involved identifying and removing all factors not relating to local geologic bodies. The challenge, therefore, is to determine what portion of the gravity differences between one location and another is pertinent to the interpretation and what part is a systematic change unrelated to the geologic target. The gravity correction process is given by:

Complete Bouguer Anomaly = Observed Gravity Theoretical Gravity + Free- Air correction - Bouguer correction + Terrain correction.

$$
\text { i.e. } B A=G_{o b s}-G_{t h}+F_{a c}-B_{c}+T_{c}
$$

The common corrections carried out in a gravity survey include: drift, tidal, latitude, free air, Bouguer and terrain corrections.

Observed Gravity $\left(G_{o b s}\right)$ : Gravity readings observed at each gravity station after corrections have been applied for instrument drift and earth tides.

Instrument drift: Gravimeter readings change (drift) with time as a result of elastic creep in the springs, producing an apparent change in gravity at a given stations. The instrumental drift can be determined simply by repeating measurements at the same stations at different times of the day, typically every $1-2$ hours.

Earth's tides: Just as the water in the oceans responds to gravitational pull of the Moon, and to a lesser extent of the Sun, so too does the solid earth. This give rise to a change in gravity of up to three g.u. with a minimum period of about 12 hours. Repeated measurements at the same stations permit estimation of the necessary correction for tidal effects over short intervals, in addition to determination of the instrumental drift for a gravimeter.

Latitude correction $\left(G_{t h}\right)$ : Correction subtracted from $G_{o b s}$ that accounts for Earth's elliptical shape and rotation. The gravity value that would be observed if Earth were a perfect (no geologic or topographic complexities), rotating ellipsoid is referred to as the normal or theoretical gravity. For this survey, 1967 Geodetic Reference System formula was used.

$$
\begin{gathered}
G_{t h}=978031.85(1.0+0.005278895 \sin 2(\text { lat })+ \\
0.000023462 \sin 4(\text { lat }))(m G a l)
\end{gathered}
$$

where lat is latitude

Free-air correction $\left(F_{a c}\right)$ - The free-air correction accounts for gravity variations caused by elevation differences in the observation locations. The form of the free-air gravity anomaly, $g f a a$, is given by:

$$
g f a a=g o b s-G_{t h}+0.3086 h(m G a l)
$$

where $h$ is the elevation (in $\mathrm{m}$ ) above the datum (typically sea level).

Bouguer correction $\left(B_{c}\right)$ - The Bouguer correction is a correction to account for the excess mass underlying observation points located at elevations higher than the elevation datum (sea level or the geoid). Conversely, it accounts for a mass deficiency at observation points located below the elevation datum. The form of the Bouguer gravity anomaly, $g b a$, is given by:

$$
g b a=g o b s-G_{t h}+0.3086 h-0.04193 r h(m G a l)
$$

where $r$ is the average density of the rocks underlying the survey area. For this survey, the average crustal density of $2670 \mathrm{~kg} / \mathrm{m}^{3}$ was used (Osazuwa et al, 1994: Hinze, 2003).

Terrain correction $\left(T_{c}\right)$ - This accounts for variations in the observed gravitational acceleration caused by variations in topography near each observation point. Because of the assumptions made during the Bouguer Slab correction, the terrain correction is positive regardless of whether the local topography consists of a mountain or a valley. Terrain corrections are calculated using a combination of the method described by Nagy (1966) and Kane (1962).

The gravity data were subjected to aforementioned gravity corrections (instrumental and tidal drift, free-air, bouguer, Terrain and latitude) to remove all effect not related to the subsurface materials and the complete Bouguer anomaly map (Fig 7) was produced. Also the residual Bouguer anomaly map (Fig 9) was generated using 2nd order polynomial fitting which remove the regional Bouguer (Fig 8) from the complete Bouguer.

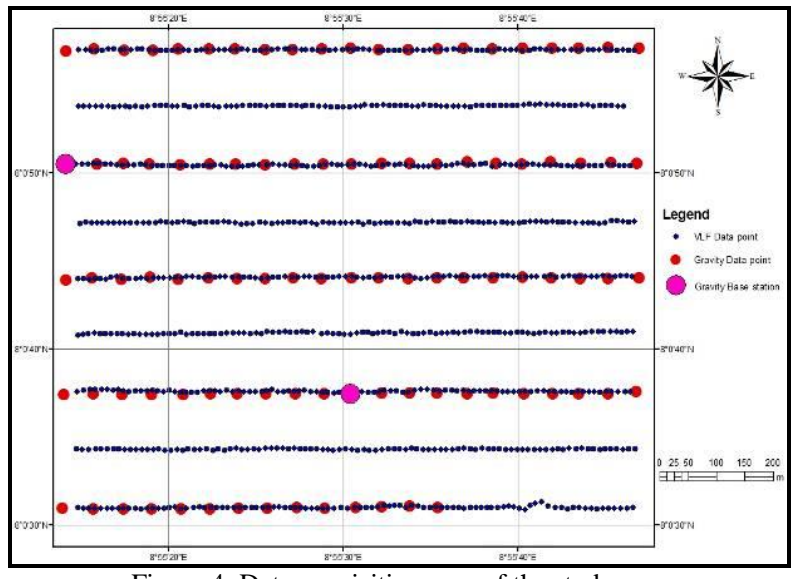

Figure 4: Data acquisition map of the study area

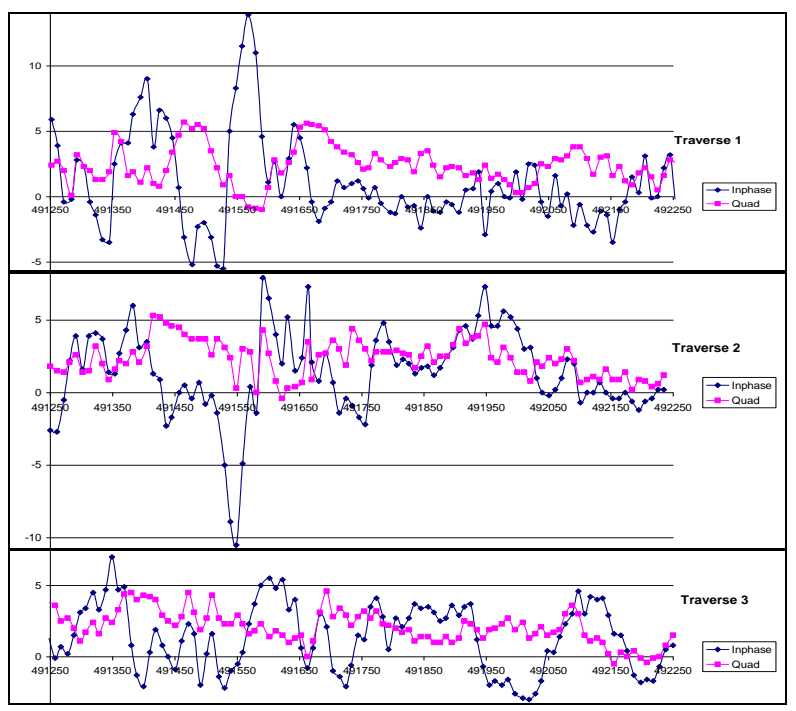



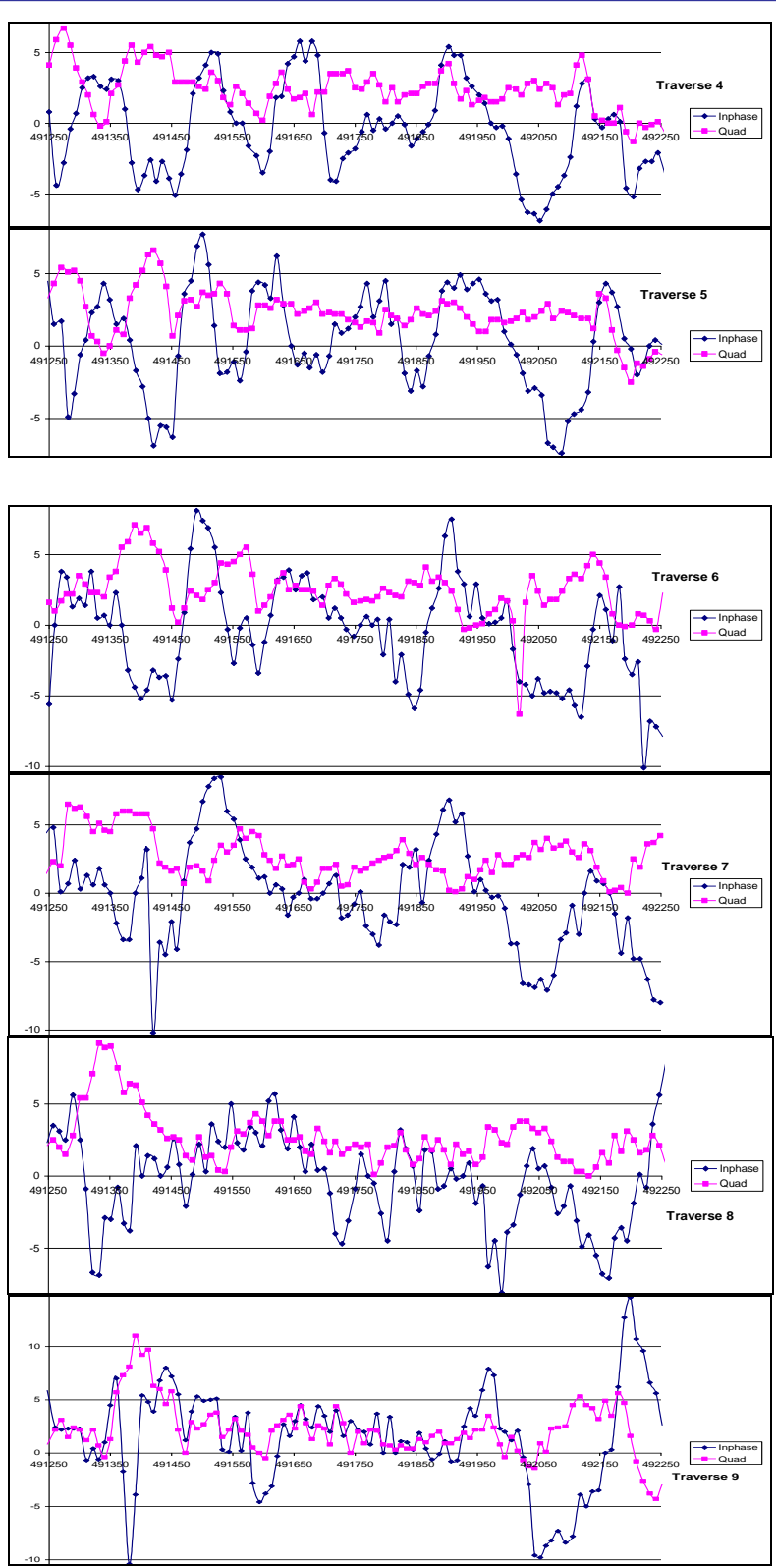

Figure 5: Plot of In-phase and Quadrature against the station position

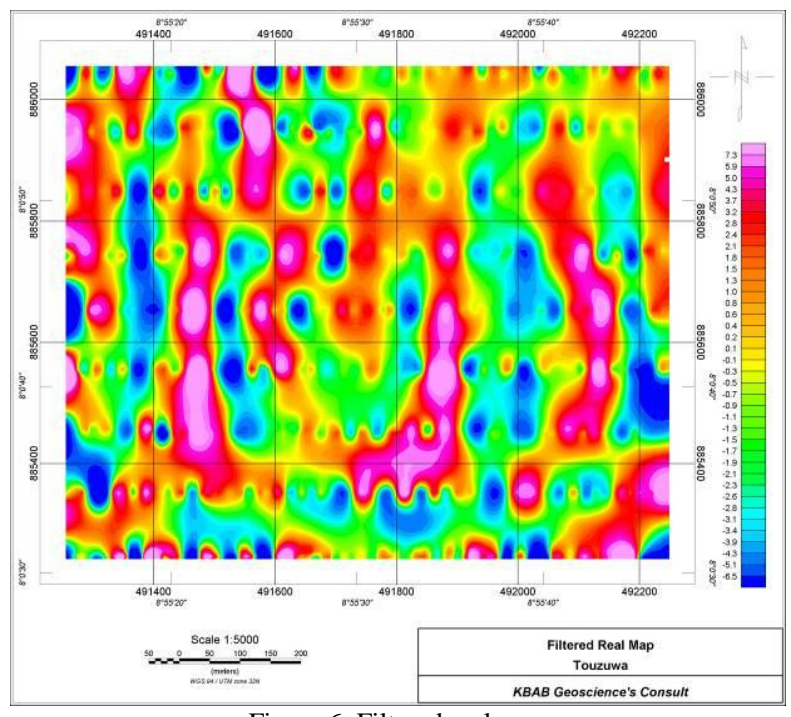

Figure 6: Filtered real map

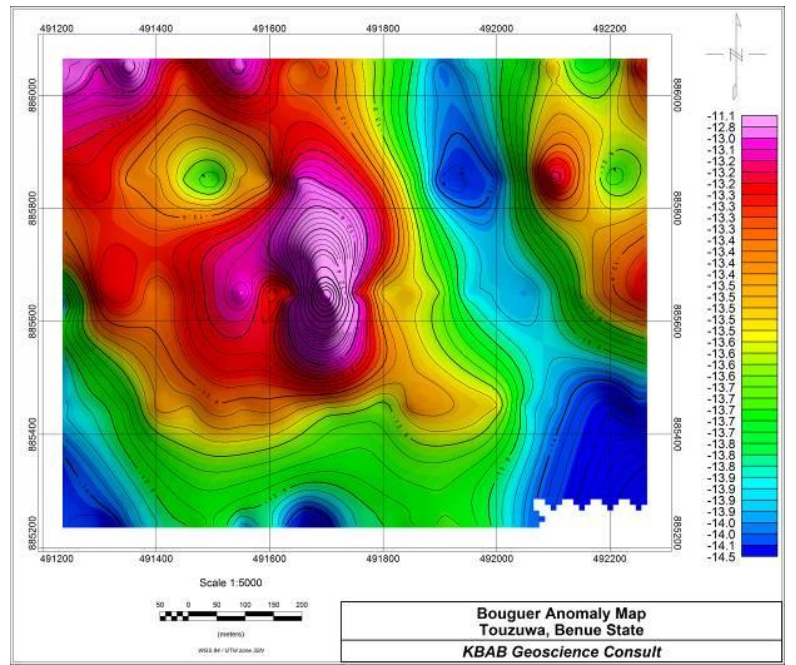

Figure 7: Bouguer Anomaly Map of the study area

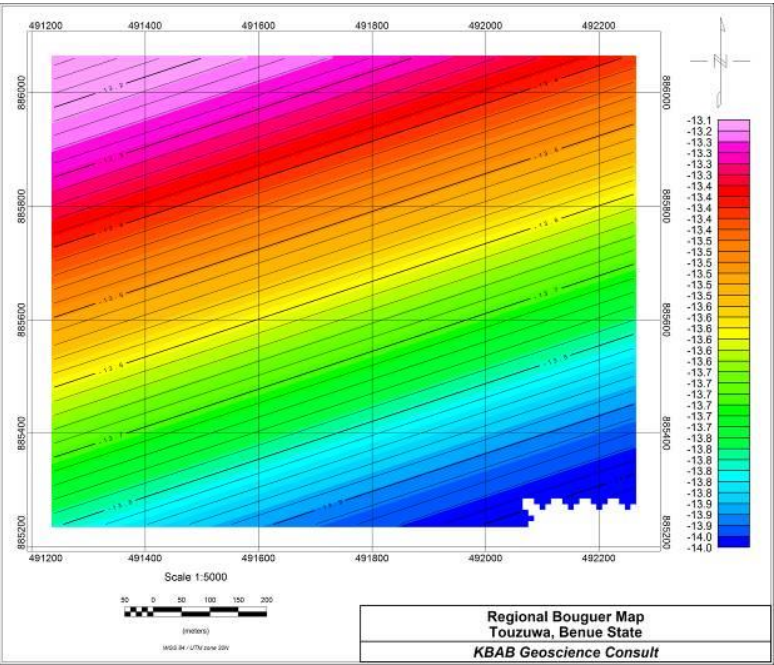

Figure 8: Regional gravity Map of the study area

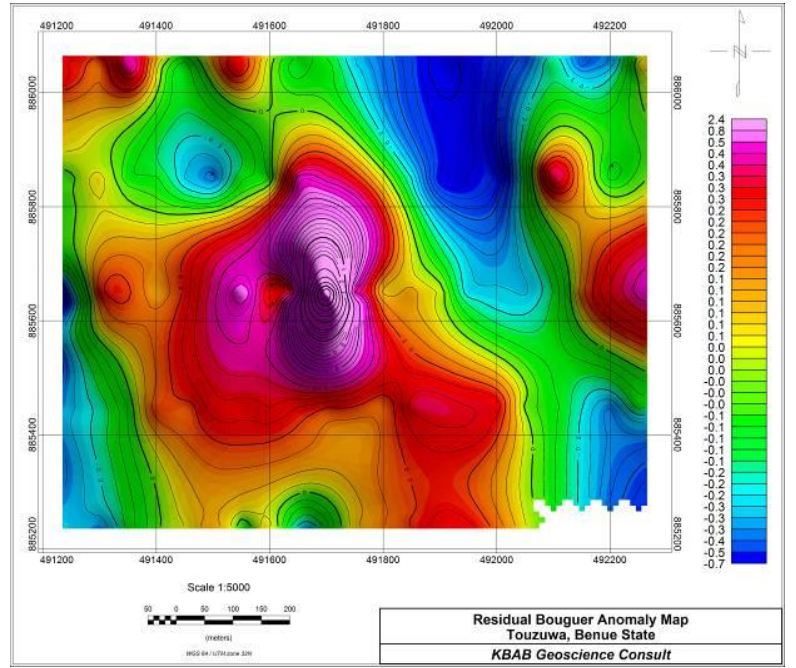

Figure 9: Residual gravity anomaly Map of the study area 


\section{RESULTS AND DISCUSSION}

From the plots of In-phase versus Quadrature as shown in Fig 6, the cross-over points are most probably indicating top of conductive bodies. These bodies, suspected to be mineralized veins all trend averagely and nearly in the North-South direction (Fig 6).

According to Olorunfemi et. al., 2005, a typical North South VLF-EM real component anomaly over an inclined contact, vein or approximation of a thin conductor is Sshaped with the negative amplitude shoulder displayed on the northern flank. The inflection point of such an anomaly is located directly on top of the contact or conductor, if it is vertically dipping. The inflection point is slightly displaced towards the down dip side, if the body is gently dipping. In this case, the anomaly is asymmetrical and the anomaly shoulder (+ve or -ve amplitude) is maximum on the down dip side

The Filtered Real maps show some distinct approximately $\mathrm{N}-\mathrm{S}$ trending structures, which is consistent with the known mineralized structural trend in this part of Benue trough. Some are conductive while others are not.

Bouguer anomaly ranges from -14.5 to $-11.1 \mathrm{mGal}$ while the residual ranges from -0.7 to $2.4 \mathrm{mGal}$. Although the range of the gravity Bouguer and residual Bouguer anomaly is quite low but the results from the gravity survey still reflect that the Bouguer and the residual anomalies are high in some locations and low in others. However, the ore minerals even though having typically high densities, is seldom used for the direct location of ore deposits using the gravity method because the concentration of ore is usually too low or the ore bodies too small, however in this exercise, gravity method was applied as a complimentary geophysical tool VLFelectromagnetic method.

A wide range of linear structures was revealed in all the study area. it can be inferred that most of these structures are most probably mineralized veins with varying degrees of characterization. Their responses to physical parameters also revealed that some are conductive while others are nonconductive. Interestingly, most of these veins also gave high Bouguer anomaly indicating presence of dense materials.

Both the gravity and VLF survey has confirmed the presence of N-S structures in this part of the middle Benue Trough. From the foregoing, the following conclusions were therefore drawn: the investigations delineated many linear structures most of which are conductive while some are nonconductive. Majority of the structures are suspected mineralized veins since the orientation is consistent with the direction of most mineralised veins in this part of Benue Trough. Due to their seemingly high Bouguer response, such vein may contain dense minerals which are readily available in this area of the Basin.

\section{REFERENCES}

[1] Benkhelil, J. (1987): Cretaceous Deformation Magmatism and metamorphism in the Lower Benue Tough, Nigeria. Geol. Journ. Vol. 22, pp. 467-493.

[2] Eberle, D., 1981: A method for reducing terrain relief from VLF-EM data. Geoexploration 19, $103-114$

[3] Fraser, D.C., (1969): Contouring of VLF-EM data. Geophysics 34 958-967.

[4] Hinze, W.J., (2003): Bouguer Reduction Density: Why 2.67? Geophysics, 68,1559-1560, doi 10.1190/1.1441130.

[5] Kane, M.F., (1962): A Comprehensive System of Terrain Corrections Using a Digital Computer. Geophysics, 27, no 4, pp. 455-462.

[6] Morelli, C., Ganter, C., Honkasalo, T., McConnel, R.K., Tanner, J.G., Szabo,G., Uotila,U. and Whalen, C.T. (1974): The International gravity standardization Net 1974 (IGSN 71).

[7] Nagy D., (1966): The Prism Method for Terrain Corrections Using Digital Computers. Pure Appl. Geophys. 63, 31-39.

[8] Nigerian Geological Survey Agency (2006): Geological and Mineral Map of Benue state.

[9] Nigerian Geological Survey Agency (2006): Geological and Mineral Map of Nasarawa state.

[10] Olorunfemi, M.O.; Fatoba, J.O and Ademilua, L.O. (2005): Integrated VLF-Electromagnetic and Resistivity Survey for Groundwater in a Crystalline Basement Complex Terrain of Southwest Nigeria. Global Journal of Geological Sciences, Vol. 3 (1), pp. 71-80.

[11] Offodile, M.E., (1976): The geology of the Middle Benue, Nigeria. Uppsala: (Paleontologiska inst., Uppsala Universitet), 1976.

[12] Osazuwa, I.B. (1985): The Establishment of primary gravity Network for studies in Nigeria, Unpublished Ph.D. Thesis. A.B.U., Zaria, Nigeria.

[13] Osazuwa, I.B., (1992a): Logistics and Operational Techniques in Gravimetry In: Tatavus, G. (Ed.). Proceeding of the First International Conference on Surveying and Mapping, National Cartographic Centre, Tehran, Iran, 11: 15-41.

[14] Osazuwa, I.B., (1992b): The Nigerian Standard Gravimeter Calibration Line. Survey Review. U.K. Vol 31, No.245. Pp 397-408.

[15] Osazuwa, I.B., onwuasor, E.O., azubike, O.C. and okafo, B.J.O (1994): Regional Gravity Survey of Kaduna and Katsina States, Geological Survey of Nigeria Gravity Map series No. 1, 9pp.

[16] Wightman, W. E., Jalinoos, F., Sirles, P., and Hanna, K. (2003) "Application of Geophysical Methods to Highway Related Problems." Federal Highway Administration, Central Federal Lands Highway Division, Lakewood, CO, PublicationNo. FHWA-IF-04-021, Sep 2003. http://www.cflhd.gov/resources/agm/

[17] Zaborski, P.M., (1998): A review of the cretaceous systems in Nigeria. Africa. Geoscience. Reveiw. 5, 385-483

\section{ACKNOWLEDGEMENT}

We are grateful to the management of KBAB Geosciences' Consult for the technical support to carry out this study. The effort of Isong Michael, Esso Uwem, Enger Terry, Ajulo Mosi and Ogbeche Daniel is highly appreciated in course of the data acquisition. 


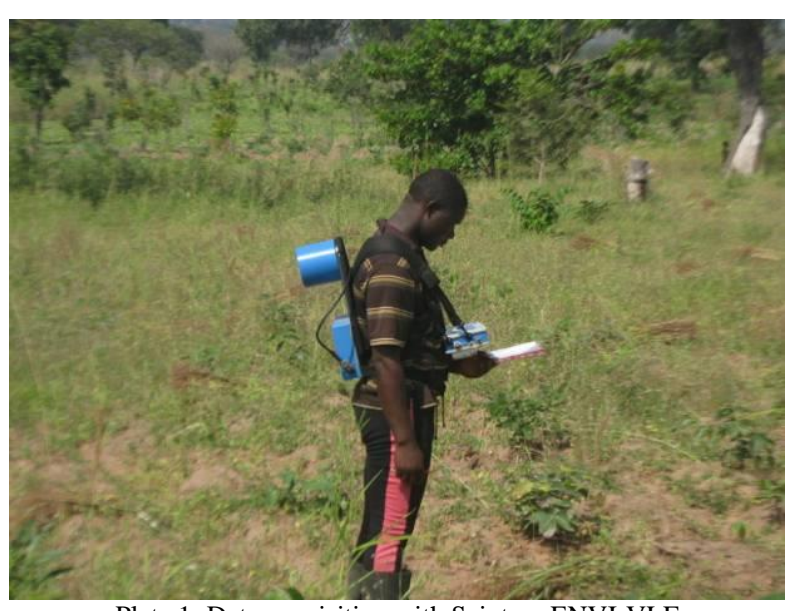

Plate 1: Data acquisition with Scintrex ENVI-VLF

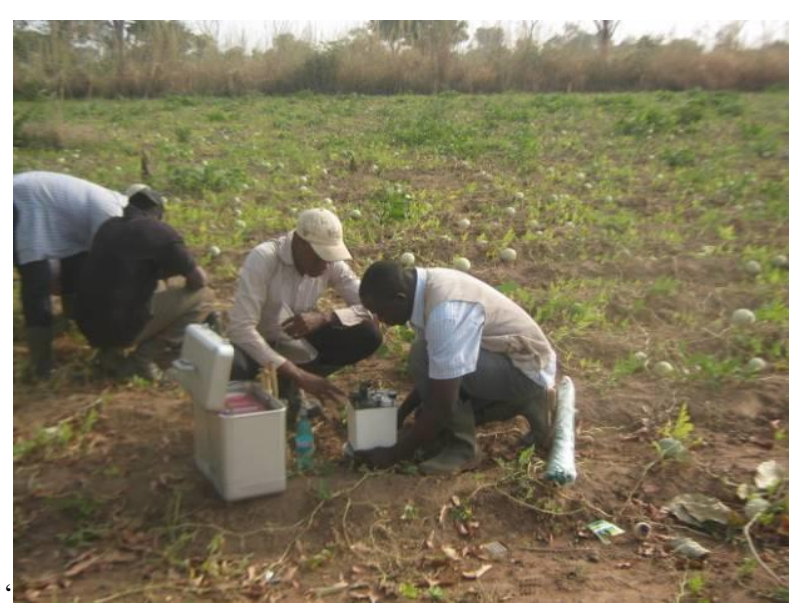

Plate 2: Data acquisition with Lacoste and Romberg gravimeter (G-512) 